Photographische Beobachtungen von kleinen Planeten.

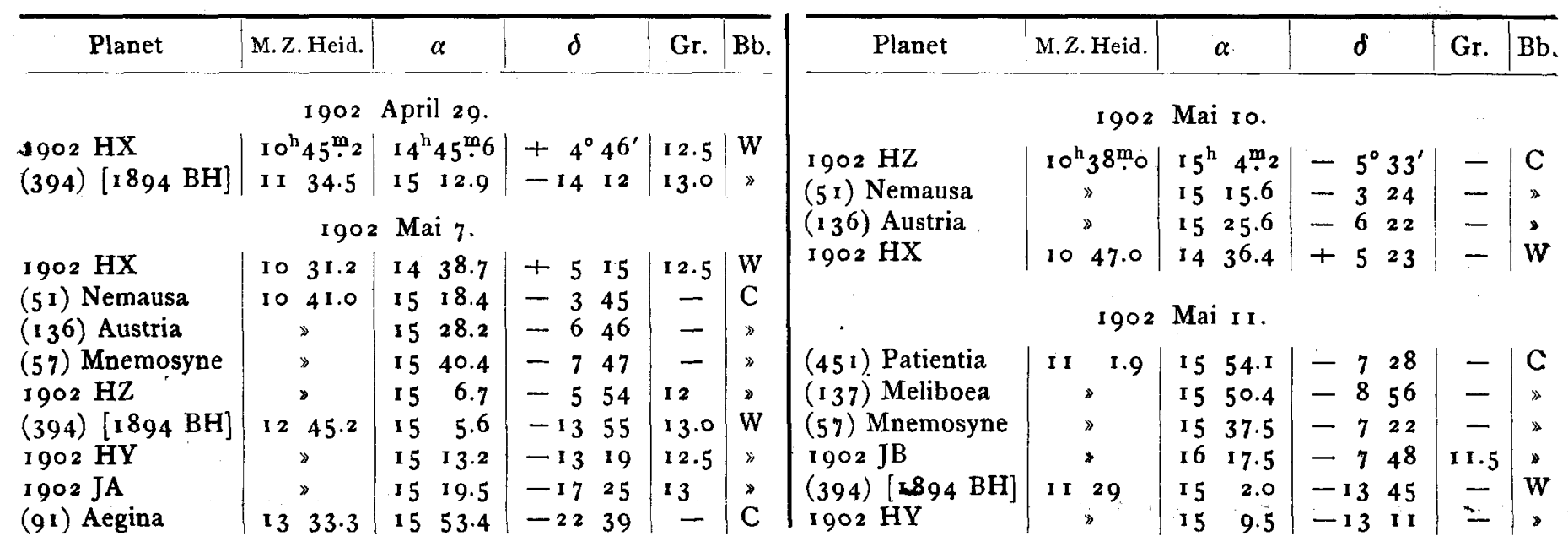

$1902 \mathrm{HX}$ bis JB sind neue Planeten; die täglichen Bewegungen der bisher nur einmal photographirten JA und

JB sind: JA $-0^{m} \cdot 7+10^{\prime}, \mathrm{JB}-0^{\mathrm{m}} .8+2^{\prime} .1902 \mathrm{JB}$ ist möglicherweise mit (469) [1901 GB] identisch.*)

Heidelberg, I 902 Mai 12.

M. Wolf.

${ }^{*}$ ) Identität nach einer Mittheilung von Prof. J. Bauschinger sehr wenig wahrscheinlich. Kr.

\title{
Beobachtungen von Planeten
}

am r 2 zölligen Refractor der Sternwarte Heidelberg.

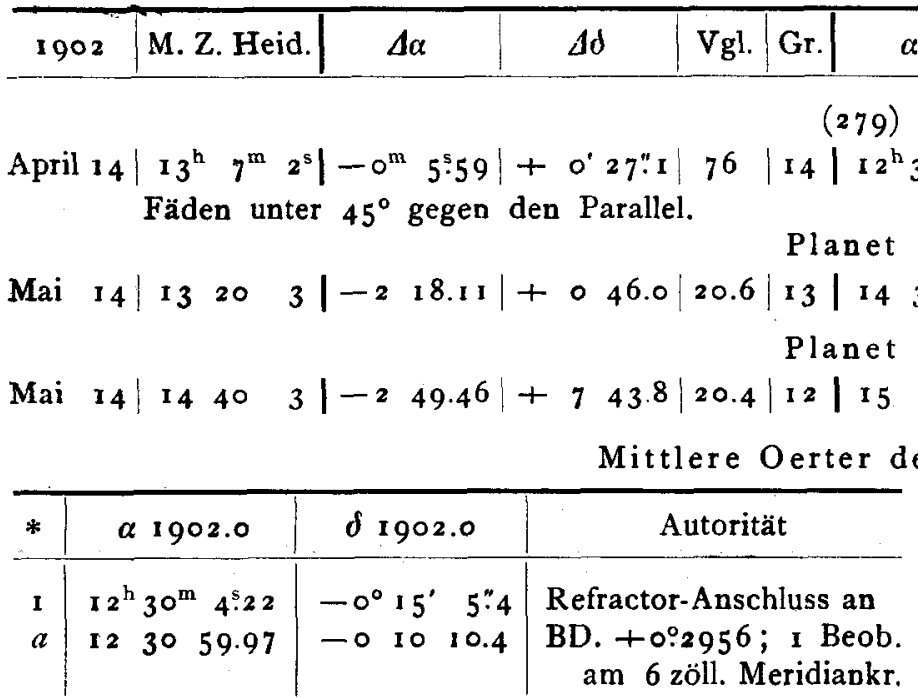

Königstuhl, 1902 Mai 16. am 6 zöll. Meridiankr.

$\alpha$ app.

\begin{tabular}{|l|l|l|l|l}
$\mid \log p . \Delta$ & $\delta$ app. & $\log p . \Delta$ & Red. ad l. app. & $*$ \\
\hline
\end{tabular}

79) Thule.

Fäden unter $45^{\circ}$ gegen den Parallel. Planet $1902 \mathrm{HX}$.

$143257.3^{8}$
Planet $1902 \mathrm{HY}$.

(451) Patientia. Corr. einer mit den Elementen im B. A. J. 1904 gerechneten Ephemeride: Mai I I $+2^{\text {s }}+0.5$.

O. Knopf.

Inhalt zu Nr. 3793. H. v. Zeipel. Elemente und Jupiterstörungen des "Planeten (10) Hygiea. I. - F. Pinloux. Positions de petites planètes. 5. C. T. Whitmell. Saturn visible through the Cassini Division. 9. - K. Graff. Bemerkungen zu dem Stern BD. +21 934 . II. - K. Graff. Ortsbestimmungen zu neuen veränderlichen Sternen. I I. - F. Comas Solá. L'étoile $\theta$ Orionis. I3. - H.Batter. mann. Beobachtungen der Nova Persei (Ch. 1226). I3. - F. Ristenpart. Planet (1 13) Amalthea. 13. - M. Wolf. Photographische Beobachtungen von kleinen Planeten. I5. - L. Courvoisier. Beobachtungen von Planeten. I5. - $O$. Knopf. (451) Patientia. 15.

Geschlossen 1902 Mai 2x. Herauggeber: H. Kreutz. Druck von C. Schaidt. Expedition: Kiel, Niemanngweg ro3. 